\title{
Why it is not strongly irrational to have children
}

\section{Søren Holm}

\author{
Response to: A rational cure for prereproductive stress syndrome
}

1 nis interesting paper Matti Häyry identifies a new disease "prereproductive stress syndrome" as well as a cure for the condition in the form of philosophically based counselling that the desire for having a child is irrational.

Few now hold the belief that an engagement with philosophy has strong therapeutic effects (even fewer when they have met real life philosophers), but this in itself is not enough to reject Häyry's plea for a more directive form of counselling before reproduction.

Let us therefore briefly look at the first of his main arguments for the conclusion that having children is irrational, since it relies on no explicitly moral premises. This argument has the form:

1. Using the maximin rule for decision making is rational.

2. The two possible actions are:

a) Do not have a child-value $=0$.

b) Have a child-value can be negative (if the life of the child turns out to be very bad).

Therefore: It is rational to choose not to have a child.

Häyry himself discusses the problems concerning premise $2 \mathrm{~b}$, so I will focus on premise 1 and $2 \mathrm{a}$.

First, I think the claim that nobody will be harmed or benefited if I decide not to have a child is problematic. It may be obvious that the child will not be harmed or benefited in this situation because it will not exist, but it is not equally obvious that no one else will be harmed or benefited. Others can be affected in a number of ways.

If I already have a child s/he can be (will be) affected by the arrival of a new sibling if I choose to have a second child, but this means that s/he will also be affected by my decision not to have a child (unless we uphold a strong act/ omissions doctrine).

The cumulative effects of not having children will also create effects on others. If we are all convinced by Häyry's arguments, and manage to act on them the number of children will fall precipitously (children only being conceived by "accident" or due to prudential or akratic failure†).

This will have a range of effects, including effects on the size of the pension professor Häyry can reasonably expect to get. He himself will therefore be affected either positively or negatively by the cumulative effects of individual "rational" choices.

Let us move on to consider the exact meaning of premise 1 , the claim that the maximin rule for decision making is rational. First we have to distinguish between two claims "the maximin rule for decision making is the only rational rule" and "the maximin rule for decision making is a rational rule". The premise Häyry needs to show that it is irrational to have children is the first stronger claim, that the maximin rule is the only rational decision making rule. That claim is implausible, however, as it would require us never to perform an action with a possible negative net consequence, if there is another possible action with no negative net consequences (on pain of irrationality). Given the ubiquity of food borne micro-organisms I should then never eat food that had not been fully sterilised in the autoclave.

Häyry writes that "Reasonable precaution dictates that we should not pick out policies, or courses of action, which can realistically have disastrous consequences" (page 377). But this claim is also ambiguous, because its plausibility depends on what he means by "disastrous consequences". There is a difference between "the decision to serve red wine had disastrous consequences, the stain from the bottle knocked over could never be removed from the dining room carpet" and "the decision to declare war on Serbia had disastrous consequences, since it set in motion the first world war". Both sentences can be true, but only because "disastrous consequences" is ambiguous. I take it that professor Häyry would not argue that we should introduce a blanket policy never to serve red wine, because choosing another policy could have disastrous consequences? Can having a child realistically create disastrous consequences in the

† Akratic failure is what happens when one suffers from akrasia or weakness of will and does not act as one ought to act. stricter meaning of the term? I do not know, but we are at least owed an argument to that effect.

If the maximin rule is only one of the rules of rationality, then all Häyry succeeds in establishing is that it is not irrational to decide not to have children, but that is a very different conclusion from the strong conclusion we would need to counsel directively against conception and childbearing.

There is another and deeper problem in Häyry's first argument, and that is that it elides the difference between value to me and value in general as a basis for rational action. Rawls's argument for the maximin principle is, as Häyry correctly notes: " $\ldots$ that it is rational, under uncertainty about one's own place in a future society, to choose political institutions which can be expected to benefit those who turn out to be in the worst position in that society" (page 377, my emphasis). What the persons behind the veil of ignorance contemplate are decisions that will affect themselves, and they therefore have self regarding reasons to be concerned about the outcome. Having a child, however, at least in the way it is analysed by Häyry, is an essentially other regarding action. Häyry's argument would not change if we contemplated putting up the child for adoption just after birth, or if we only contemplated creating embryos to donate to childless couples. In both of those cases we could still end up being involved in a chain of actions that led to the creation of a child with a very bad life (premise $2 \mathrm{~b}$ above). Whether $\mathrm{I}$, as a parent experience this is immaterial to Häyry's argument. It is only the bad outcome for the child that matters in generating the negative value of $2 \mathrm{~b}$, and the alleged obligation to avoid it. But why should I let what happens to others matter in my decision making? Unless Häyry can show that it is rational to be other regarding (which is very close to showing that it is rational to be moral, a proposition he implicitly denies), the whole structure of his argument collapses.

J Med Ethics 2004;30:381.

doi: 10.1136/jme.2003.004762

Correspondence to: S Holm, Cardiff Law School, Cardiff University, PÓ Box 427 Cardiff, Wales; HolmS@Cardiff.ac.uk 